\title{
A STUDY OF ATTRIBUTES OF CHILDREN WITH LEARNING DISABILITIES
}

\author{
APARNA MATHUR ${ }^{1} \&$ S.K. MAHTO ${ }^{2}$ \\ ${ }^{I}$ Research Scholar, Sunrise University, Alwar, Rajasthan, India \\ ${ }^{2}$ Supervisor, Sunrise University, Alwar, Rajasthan, India
}

\begin{abstract}
This research paper primarily focuses on the most commonly-occurring attributes in a child who is suffering through learning disability. In most of the cases, an individual does not end up featuring deficiency in all the areas of potential disability. Therefore, it is important to understand that different characteristics that child with disability showcase and one can recognize the appropriate adaptation cycle for the healing process of the same. The research paper found that troublesome issues in present evaluation structure can mold delivery system and lessen the execution of effective interruptions for children and youngsters with learning and behavior issues. There is requirement of adaptations while focusing on effective interventions and assessment of results.
\end{abstract}

KEYWORDS: Learning Disability, Attributes, Special Needs, Special Education

Received: Jun 01, 2020; Accepted: Jun 20, 2020; Published: Jun 30, 2020; Paper Id.: IJMPERDJUN2020137

\section{INTRODUCTION}

Individuals that fall in the children category, while also consisting of a learning disability or two belong to a diverse group. The young kids are varied individuals, each of them representing unique issues with learning in several different areas. For instance, one kid who has a problem with reading English language sentences in the right manner has a different problem in comparison to another child who has a tough time writing sentences in English.

When it comes to learning abilities, they can carefully be distinguished in three categories, i.e. Mild, Moderate and Severe. Different student has a different method of coping. According to a study by Bowe (2005), different individuals learn to adjust to learning disabilities quite well [1]. In fact, they are so good at it that more times than often, they don't fit into the disability bracket at all. At the same time, there are many other students who face a difficult time when it comes to carrying out simple tasks in life. Regardless of whether these differences exist or not, learning disability is something that is with an individual right from his/her childhood and will not cease to exist till the end of his/her life [2]. However, many of those who end up demonstrating these kinds of behaviors are progressive at carrying out classroom activities. As per Smith (1979), there are several factors about one's behavior that needs to be taken into consideration, for instance its quantity, intensity as well as its duration [3]

\section{ACADEMIC ACHIEVEMENT DEFICITS}

The most commonly-occurring incident when it comes to children that represent learning disability is that they face a difficult time coping up with their academic performances. The problems start emerging the surface right from elementary school days. One can observe a distinctive discrepancy in students that suffer through this condition [4]. It may come across as puzzling for teachers as even though the students appear just as normal as other children who are devoid of this condition, still the former ends up carrying forward an unexpectedly slower rate of growth. These 
issues end up reflecting in the individual's primary grades, formal schooling as well as senior college.

There are numerous categories that children with academic deficiency can face problems under. These factors include written discourse, problem-solving and forming as well as reading sentences. There are children who end up having a problem with only one academic area; however, there are many others who end up facing issues with all the three regions.

\section{READING DEFICITS}

Reading is perhaps one of the primary methods through which the human civilization exchanges information. Therefore, the activity is given utmost importance right from the beginning of school [5]. It has therefore, ended up resulting in being associated with academic failure. One cannot deny the fact that the activity of reading is rather complex by nature. One requires the right set of skills to read the sentence formation in the correct form.

Difficulty in reading occurs with children who have learning disabilities in more than one area of their respective academic performances. Notably, it is most visible in majority of the students who have a learning disability. According to a study by Brown and Ann (1989), approximately ninety percent of the students with learning disability face struggle when it comes to reading [6].

More times than often, many are led to believe that the problem with reading essentially occurs when the individual is lacking appropriate language skills. In other words, the person has a tough time understanding the speech flow, how the words are used and the phonological awareness as a whole.

According to the information by Campbell (2005), it is not difficult to understand why phonological problems exist in the core of reading difficulties [7]. Individuals, who face struggle when it comes to breaking words, will have a more difficult time reading complete sentences. Moreover, there is concrete proof that English readers are more likely to develop such an issue with their languages in comparison to others. In fact, the problem occurring has become so common in English-speaking countries that people are led to believe the same.

Our society is such that it gives a high level of importance for skilled reading. Therefore, those who are not necessarily skilled readers in school or at their workplace are looked down upon. As noted by Cartter and Synolds (1974), following given is the main reason why a child might be facing problem while attempting to learn how to read [8]:

- Error in the auditory perception of the individual, devoid of any hearing impairment tool.

- Slow level of process when it comes to visual or auditory activities.

- Lack of ability to understand the different sounds of spoken words.

- Very little or no knowledge of the importance and purpose of reading activity.

- Unsuccessful at realizing the key elements of words, sentences or paragraphs as whole.

- Lack of understanding when it comes to identifying which unit represents which speech.

An increasing number of recent researches have gone on to take the wraps off major details about the true nature underlying behind an individual's learning disability especially when it comes to reading. As per experts children face the most difficult time while deciphering words [9]. They do not face as difficult a time while processing text. 


\section{ORAL READING DIFFICULTIES}

Oral reading difficulty is when the individual has a tough time in maintaining their reading fluency. There are different ways of defining reading fluency. However, the easiest one can be the one wherein the same is gauged on how accurate his/her reading is. As noted by Davidson (1934), oral reading is an important indication towards one's reading ability. Students who have a fluency problem will go on to read each and every word out loud without representing any form of inflection of rhythm [10]. These end up being related to different patterns of the spoken language when the same is compared to printed words. Students who end up being weak in one particular area are often in fear of being asked to read aloud in class.

According to the research conducted by Espin and Sindelar (1988), the most commonly-occurring reading problems consist of the following given aspects [11]:

- Omitting: This takes place when a student chooses not to read or rather skip specific words that he/she has a difficult time reading.

- Substitution: Students ends up substituting the difficult word with another word from the same passage or an alternative that he/she has in his/her minded.

- Mispronunciation: If the student is forced to pronounce the word, then he/she ends up mispronouncing it and it does not necessarily bear any proper resemblance to the appropriate readings.

- Hesitating: The student showcases signs of nervousness or hesitation when it comes to reading or pronouncing words.

- Inversion: An individual completely changes the order in which the sentence has been formed.

\section{ANALYZING ORAL READING MISCUES}

An oral reading is often compared to and defined as a miscue. For the uninitiated, a miscue is one such occurrence wherein an individual reading something from a page is completely different from what is actually presented on the page. According to Frostig and Maslow (1973), such type of distinguishes occur and end up resulting in random errors which have no necessary explanation [12]. These occurrences are purely built up by the reader himself/herself on the basis of his/her thought and language ability.

As noted by Gearheart (1973), a miscue holds a lot of importance as it has the ability to affect the meaning of a sentence formation [13]. They hold special amount of importance especially when the following incidents take place:

- The true meaning of a given statement or paragraph has drastically been changed and the student does not bother to correct it to its original form.

- In place of a word, the student makes use of a non-word.

- Only a partial word is being substituted for the word or rather, the phrase in the given passage.

- Students requires assistance at pronouncing a given word or sentence. 
Miscues don't end up holding a lot of importance when it comes to following given situations:

- $\quad$ The meaning or the sentence formation of a given paragraph remains unchanged.

- $\quad$ The student does not require assistance in reading out words or sentences.

- The student does not require correction from another individual.

- They represent a proper flow of reading dialect without much difficulty.

Needless to say, students end up facing a lot of embarrassment when it comes to oral reading problems. Their strained faces, nervousness, poor phrasing, ignorance to punctuation among other things end up causing the problem.

\section{READING COMPREHENSION DEFICITS}

Reading comprehension is another common problem that students with learning disabilities face. Children end up lacking the much-needed skills when it comes to understanding the text of a given passage as a whole. For the uninitiated, reading comprehension, in simple words, can be described as the student's ability to understand what they are reading [14]. Numerous students end up facing a very difficult time when it comes to reading comprehension. One might think that they are highly-skilled readers but in reality, they do not understand a lot about what they are reading. This can be discovered when they are asked questions about what they have read out from the passage.

\section{PROBLEMS WITH WORD RECOGNITION}

Students who represent learning disabilities often end up facing a difficult time when it comes to recognizing words. This activity is directly related to the student's ability when it comes to sight vocabulary [15].

\section{DYSLEXIA}

When it comes to learning disabilities, dyslexia is perhaps one of the most distinctive problems that is widespread amongst students. It can be defined as being a language-based disorder that goes on to be characterized by the problems that students face while decoding single words.

The problems occurring when it comes to single word decoding are more times than often, related to the age or the academic abilities of a given individual. These are not the result of when it comes to generalized development disability or sensory impairment.

In simpler words, dyslexia can be identified as being the kind of reading disorder wherein students fail to recognize or even comprehend the written words as a whole. Experts call it as being a severe impairment while an individual portrays the ability to read [4]. It does not mean that the individual does not hold normal levels of intelligence. Despite of receiving normal opportunities to read as well as an adequate and homely environment, the individuals suffering from dyslexia end up facing severe problems.

\section{MATH DEFICITS}

It goes without saying that issues pertaining mathematics are not given as much of emphasis as reading disorders, the former is starting to receive a great deal of attention in the recent past. Experts now go on to understand that mathematics difficulties are merely second to reading disabilities when it comes to comparing academic problems that students go on to face [5]. Researchers go on to estimate that roughly one out of every fourth student who is suffering from a learning 
disability ends up receiving assistance when it comes to facing difficulty with problem-solving. Therefore, it has become essential for one to understand the importance of discovering a method that helps individuals get around with such problems.

\section{ANALYSIS AND INTERPRETATION OF MATH SKILLS}

According to a recent research conducted by Campbell (2005), problem-solving is among the top subjects in school that result in error analysis [7]. The main reason behind this is that students end up preferring writing about the tasks over everything else. Therefore, it goes on to represent a more permanent record of what their work really is. Apart from this, students end up giving at least one correct answer. Therefore, the result becomes unambiguous by nature.

At the moment, the most-used error analysis when it comes to mathematics problems is the gauging of computation skills. As noted by Cole (1992), such things are differentiated on the basis of systematic computation errors or the kind of errors that are purely unintentional and random by nature [16].

\section{DYSCALCULIA}

When it comes to arithmetic, activities such as identifying numbers and symbols as well as memorizing facts while aligning the numbers in the correct form is involved. Apart from this, it also includes the understanding of abstract concepts such as fractions as well as place values. It becomes difficult for children that feature a disorder pertaining development arithmetic to cope around such problems. Such problems usually end up showing up earlier in stage and disabilities that involve reasoning are highlighted later in stage.

\section{WRITTEN EXPRESSION DEFICITS}

Different individuals that represent learning disability problems also often have troubles when it comes to written expressions. In fact, the issue is now starting to receive more attention as it is becoming widespread among humans. Writing is perhaps one of the most complex activities that involve the integration of a lot of things including conceptual skills as well as eye-to-hand linguistics [10]. The problem never really takes place with an individual's writing but instead, it takes place with the form.

\section{HANDWRITING DIFFICULTIES}

Handwriting is a motor activity which is a part of the process of writing. Majority of the students first learn manuscript (printing) and then they proceed towards cursive writing (script). There have been a few educationalists who have suggested teaching only manuscript or cursive writing but practically, the students come across many issues while learning one of them. As the children develop, their writing witnesses a change. That child tends to change emphasis from writing procedure (handwriting and spelling) to written product (already written) to communication with readers [11]. It was Gargiulo (2004) who observed that in the initial stages, children are more focused on being skilled so they can be proficient in the mechanical factors of composition (spelling and handwriting), as they become more mature and develop, they know how to organize and put forth their ideas in a well-structured way [2]. The children who face learning disabilities cannot match up to the level of the non-disabled children. It has been noticed by researchers that the ones with learning disabilities tend to make sentence structures which are less complicate, present fewer ideas, generate the paragraphs which are not arranged properly and write the stories which are less complicated. 


\section{SPELLING PROBLEMS}

The capacity to make use of the letters to structure words considering the accepted usage is known as Spelling. Few teachers and school personnel consider spelling skills as equal to the remaining academic capabilities. If a child cannot spell properly, it does not mean that the child is going through learning disorder. If a child has poor spelling skills along with poor reading skills then it is a matter to be worried about. It can be seen that majority of learning capabilities which are needed for good spelling are the ones which help the students to be good readers. Learning how to spell is a progressive procedure and youngsters face numerous phases when they start to obtain written language abilities [12]. It is the preschool where writing starts and youngsters notice it then start to do it themselves by copying it the writing.

There is a learning disability related to spelling which is known as Dysorthographic. The people with this type of disability go through hard times while using the signs from various sources which help in making a decision regarding appropriate spelling of a word. Students with learning disabilities face hart times in learning and implying phonics instructions, picturing words precisely, knowing the mistakes in misspellings. It is pretty common to see children with learning disabilities making spelling mistakes for same word on same paper in various ways, be it the student of fifth grade or a student of college. The spelling mistakes such as there, there and they're for 'their' are quite common.

\section{LANGUAGE DEFICITS}

The students who have learning disabilities usually have a hard time in mechanical and social usage of the language. There are particular mechanical arrears which are usually seen in three regions [2].

Syntax: Rule systems that determine how words are organized into sentences Semantics. Word meanings

Phonology: The study of how individual sounds make up words.

Topics of oral expression and listening intellectual capacity are usually where language arrears can be seen and these two topics have the power to regulate the skills to communicate with people due to which if there is any arrear in one of them or both of them then it can have a big influence on life quality of a student with LD and their educational life [3]. According to the past researches, more than $60 \%$ of students with learning disabilities are going through some sort of language illness [4].

\section{DISORDERS OF ATTENTION}

Attention is considered to be an essential ability in the process of learning. According to the suggestion of Cole (2005) if one has to be an efficient learner, then they should know how to give attention, focus and give attention in a proper way, maintain the attention as per task requirements and change their attention when needed to be [9]. The arrears in such topics lead to major influence on every other topic of school. If the children are not giving proper attention then they will not be able to reply to the questions in a proper way, they cannot follow the instructions or note anything while a lecture is going on. There are social issues which arise if students are being interrupted and not listening to classmates. There has been estimate made that number of students facing learning disabilities with the attention issues vary from $41 \%$ to $80 \%$ [3].

Attention issues in the children with LD are usually described as short attention span. Short attention span is nothing but a situation when a person is not able to focus on a particular activity for more than few seconds or minutes. 


\section{OVERVIEW OF ADHD}

In the situation of Attention-Deficit Hyperactivity Disorder, it can be difficult for an individual to sit still, behave themselves and focus and such problems often start before 7 years of age thought they might not be observed until the time child is of a certain age. Doctors are still not able to find the reason of ADHD though the researches who are experts in the study of brain, they are close to finding the reason. According to them, few ADHD patients lack particular chemicals known as neurotransmitters in their brains. Neurotransmitters are the chemicals which are helpful in controlling the behavior. ADHD is not caused because of parents or teachers or peers but there are certain steps which parents and teachers can take if they want to help a child with ADHD. Around 5 out of 100 children in school might be going through ADHD and it is possible that boys are going through ADHD three times the girls are. Three major indications of ADHD are: 1) Issues while paying attention; 2) Hyperactivity; 3) Impulsivity.

\section{ACHIEVEMENT DISCREPANCY}

The students who are provided special educational facilities under LD category are a diverse group with many resemblances but it should be kept it mind that the important describing characteristic of students with LD is specialized and there is a shortage of noticeable accomplishment in the overall intelligence [5]. The students who have learning disabilities are not able to function up to the expectations on the basis of measured ability. There have been some instances in literature where it has been tried to count differences between academic achievement and academic abilities for the students with learning disabilities yet that particular field does not have a clarification which is universally approved [13]. In the initial school years, the children who have learning disabilities might be noticed being two to four years behind their mates in academic achievement levels and there are also students who are even more behind in education. Because of this depressing structure, the students are forced to drop out of high school or they are not able to complete their graduation while still being unable to be skilled in basic reading, writing or math skills [15].

\section{CAUSES OF LEARNING DISABILITIES}

Due to the relative factors, there are learning issues noticed in children and few of those factors are inside children while remaining are in surroundings.

\section{PHYSIOLOGICAL FACTORS}

Basic reasons for learning disabilities can be brain damage, insignificant brain dysfunction and central nervous system facing issues.

\section{GENETIC FACTORS}

With the help of outcomes of past research as evidence, it can be said that hyperactivity and learning disability is in the family too sometimes. Gerber (2012) noticed $88 \%$ of the families of dyslexic children going through same issues [14].

\section{DEVELOPMENTAL FACTORS}

Developmental disabilities can start at any point through the course of developmental period and they often remain there through the entire lifetime. Majority of the developmental disabilities start prior to birth of a baby though in some cases, it can arise after birth due to some kind of injury or infection. Complicated mixture of factors can also lead to developmental 
disabilities and those factors comprise of genetics; health and behaviors of parents like drinking or smoking in the time of pregnancy, birth issues, the infections which mother can go through while she is pregnant or any infection which baby may have in his or her initial years.

\section{EDUCATIONAL FACTORS}

There are particular educational factors on the parts of teachers and students both which can lead to learning disability. Teachers with no skills and training, insufficient and incorrect teaching attitude and too high or too low expectations from students can lead to learning disabilities in children. Meager instructional programming, imprecise teaching ways and shortage in motivational practices can also be the reasons of learning disabilities in children.

\section{ENVIRONMENTAL FACTORS}

Environmental support in learning and its requirement has been summarized by Maslow (1954) and it was seen that there are many environmental factors which caused learning disability such as:

- Nutrition, health and safety.

- Sensory stimulation.

- Language stimulation.

- Emotional and social development

\section{ASSESSMENT AND EVALUATION OF DISABLED LEARNERS}

Once a teacher or parent realizes that there is a need to start the procedure of evaluating special educational requirements of students, it starts. Exceptional students are evaluated on daily basis because of their daily educational programs to know about the things which are apparent and to record how much development there has been. Evaluation is quite important for the exceptional students as it is useful for the teachers to make a decision on who is in need of special education facilities. Testing has a huge part to perform in the evaluation procedure as through testing, teachers and school staff can gather the data and decide what should be done to particular students [8]. The main aim of evaluation is the competence of development of students for certain outcomes and on the extent till which students require special programs and facilities. Along with testing one can also collect data by noticing the behavior of students during their interviews or by appraising the collection of work samples.

\section{SCREENING}

In the procedure of Screening, the data is gathered through which it can be decided if there is need of thorough evaluation.

\section{EARLY SCREENING}

There is a screening process done with children before they are admitted into the kindergarten or first grade so it can be known about their reading abilities in language, intellectual and motor progress along with social and emotional progress and social and emotional functioning. In some cases, children also go through vision and hearing screening tests. There are students too who are rejected to take admission in school if their score is low in the screening test. 


\section{LATER SCREENING}

In the later screening, the cut-off scores are on the basis of average performance of students at different ages or different grades. If the scores of a student signs that they need a special requirement, they are referred for psycho educational evaluation where the tests are done to know particular reasons for performance of students.

\section{CURRICULUM BASED ASSESSMENT}

In this process, the instructional requirements of a student are known on the basis of present performance of the students in their present course. There is direct observation in such type of assessment along with the analysis of learning environment, analysis of procedure which students have used to complete the tasks, evaluation of students. This type of assessment is effective, genuine and dependable to make decisions as it can be useful for the teachers on the teaching subjects [6].

\section{INSTRUCTIONAL ANALYSIS}

Instructional analysis tells us about the degree to which a student's poor performance is caused because of poor instruction and tells us about the potential solutions for the issue. This type of analysis comprises of systematic analysis of the need of instruction which comprises of types of demands on the learner.

\section{PERFORMANCE ASSESSMENT}

In the performance assessment, the information is collected regarding the students' performance by assigning them an individual or group task.

\section{SENSORY ACUITY-TESTING VISION AND HEARING}

Here the visual tests are done on the usual basis to evaluate the students facing hard time in school. An edition of Snellen char, Snellen E is applied to evaluate preschool students and the students who cannot read. To screen the children of schools, The Timers vision Tester is used. To hear acuity, audiometer can be useful as pure-tone audiometer can produce pure tones at various frequencies and various loudness scales. Informal evaluations of sensory acuity are made by teachers where they observe the way students act when the questions are asked to them.

\section{WHAT A TEACHER CAN DO FOR STUDENTS WITH LEARNING DISABILITIES}

- Learn about child and learning disability

- Make use of numerous learning styles and various types of communicating guidelines

- Avoid lengthy directions

- Make use of approaches to help students remember

- Break down tasks in the smaller steps

- Provide additional time for schoolwork and tests

- Allow the student with reading problems to use textbooks on tape or similar devices 
- Allow the student with listening difficulties to borrow notes or use a tape recorder

- Allow the student with writing difficulties to use a computer with spell check, grammar checks, or speech recognition

\section{CONCLUSIONS}

To sum it all up, it is pretty obvious that children with learning disabilities are a diverse group. If one child shows some features, it is not necessary that the other children should be going through same difficulties. It is important for the educators to know about every potential feature which might be noticed in children. If one knows what to look for and has the ability to recognize the common features, then they might be helpful in identification, diagnosis and evaluation of a child with possible learning disability. Knowing about these features or learning styles can cause remarkable development in academic performance, social awareness and confidence of a child with LD in classroom. Improvement in the assessment of special education in India is conferred for numerous times in last twenty years. Troublesome issues in present evaluation structure can mold delivery system and lessen the execution of effective interruptions for children and youngsters with learning and behavior issues. There is requirement of adaptations while focusing on effective interventions and assessment of results.

\section{REFERENCES}

1. Bowe (2005). Making Inclusion Work. Merrill Education/Prentice Hall.

2. Gargiulo, R. M. (2004). Special Education in contemporary society: An introduction to exceptionality. Belmont, CA: Thompson- Wadsworth.

3. Smith, D. (2004). Introduction to special education: Teaching in an age of opportunity (5 ${ }^{\text {th }}$ Ed.). Boston: Allan \& Bacon.

4. Alster, E. H. (1997). The effects of extended time on algebra test scores for college students with and without learning disabilities. Journal of Learning Disabilities, 30, 222-227.

5. Bennett, R. E., Rock, D. A. and Kaplan, B. A. (1987). SAT differential item performance for nine handicapped groups. Journal of Educational Measurement, 24, 44-55

6. Brown, P., and Ann, D. (1989). Effects of mnemonic instruction upon retention of vocabulary with learning disabled children. (Doctoral dissertation, University of Missouri, Kansas, 1989). Dissertation in Abstracts international, 50(10), 3206 A.

7. Campbell, J. I. D. (Ed.) (2005). Handbook of mathematical cognition. New York: Psychology Press.

8. Cartter, J. L. and Synolds, D. (1974). Effects of relaxation training upon handwriting quality. Journal of Learning Disabilities, 7,236-238.

9. Cole, M. (2005). Cross-cultural and historical perspectives on the developmental consequences of education. Human Development, 48, 195-216

10. Davidson, H. P. (1934). A study of reversals in young children. In L.G. Reddy, \& R. Ramar, Learning disabilities: A guide to practitioners. New Delhi: Discovery Publishing House.

11. Espin, C. A. and Sindelar, P. T. (1988). Auditory feedback and writing: Learning disabled and nondisabled students. Exceptional Children, 55, 45-51.

12. Frostig, M. and Maslow, P. (1973). Learning problems in the classroom: Prevention and remediation. In L. Harding, Learning Disabilities in the primary classroom. London: Croom Helm. 
13. Gearheart, C. K. (1973). The learning disabled adolescent: Programme alternative in the secondary school. USA: C.V. Mosby Company.

14. Gerber, P. J. (2012). The impact of learning disabilities on adulthood: A review of the evidence based literature for research and practice in adult education. Journal of learning disabilities, 45(1), 31-46.

15. Given, B. K. and Reid, G. (2005). Learning styles. A guide for teachers and parents. St Anne's-on-Sea, Lancashire; red Rose Publications.

16. Cole, K. B. (1992). Efficiency of generalization of instruction in sequential expository writing for students with any disabilities. (Doctoral dissertation, Northern Illinois University, 1992). Dissertation Abstracts International, 53(7), 2326 A.

17. Imonje, Rosemary, and Grace Nyagah. "Influence of Capacity Building of Academic Teaching Staff in Mainstreaming Disability Interventions for Students with Special Needs in Public Universities in Kenya." International Journal of Humanities and Social Sciences (IJHSS) 7.6 (2018):55-68

18. Sandhu, Puneet and Dazy Zarabi. "Self-Regulated Learning and Well-Being In Mainstream Classrooms: Focusing The Lens on Students with Learning Disability." International Journal of Educational Science and Research (IJESR) 8.1 (2018): 75-90.

19. Lai, Sofia. "Social Integration and Job Satisfaction of Employees with Disability: Comparing and Contrasting With General Newcomers." International Journal of Educational Science and Research (IJESR) 6.3 (2016): 29-36. 

